\title{
A Study on the Importance of Entrepreneurship Training for the Formation of Entrepreneurs
}

\author{
Robson Antônio Tavares da Costa, Eline Olímpia de Souza Queiroz, Aléxia Galvão Assunção \\ Department of Philosophy and Human Sciences, Federal University of Amapá, Macapá, Brazil \\ Email address: \\ ratcosta@gmail.com(R.A. T. da Costa), elineolimpia@gmail.com (E. O. de S. Queiroz), alexia.galvao2509@gmail.com(A. G. Assunção)
}

\section{To cite this article:}

Robson Antônio Tavares da Costa, Eline Olímpia de Souza Queiroz, Aléxia Galvão Assunção. A Study on the Importance of Entrepreneurship Training for the Formation of Entrepreneurs. American Journal of Applied Scientific Research.

Vol. 4, No. 2, 2018, pp. 12-19. doi: 10.11648/j.ajasr.20180402.12

Received: July 5, 2018; Accepted: July 31, 2018; Published: September 10, 2018

\begin{abstract}
This article aims to identify and analyze the value of entrepreneurship training as a tool for training entrepreneurs to open micro and small enterprises, training and for good business performance, including among young people. Historically, the training of the entrepreneur is taken as an instrument of teaching and learning, but its effectiveness is not proven due to the lack of monitoring in the labor market of those who undergo this type of learning. In view of this, the present study took as a study object the monitoring carried out in 2011 and 2012 of the participants of the Technological Enterprise - EMPRETEC 2010, promoted by the Brazilian Service of Support to Micro and Small Businesses - SEBRAE, in the city of Macapá, of Amapá, whose data are contained in the publication "Impact of EMPRETEC Training on Macapaenses participants", and are presented in a systematic way in this article. The study deals with themes such as entrepreneurship and human development, from which the scientific discussions were extracted to contextualize the problem studied, as a theoretical basis of training effectiveness. Aiming at the formation of the entrepreneurial personality, the authors' studies were used as references: David McClelland, Dornelas, Cannon-Bowers and Salas. The methodology used is to compare the performance of training participants, before and after the training. The result showed that the number of public companies and their formalization more than doubled in relation to the number of companies before the training.
\end{abstract}

Keywords: Entrepreneurship, Training, Human Development, EMPRETEC

\section{Introduction}

Entrepreneurship is an important factor in generating jobs and income and in strengthening the economy of a region. According to José Portela, Pedro Spain, Claudia Nogueira, Mário Sérgio Teixeira and Alberto "small business creation is increasingly seen as a way of activating unemployed manual labor and a way of not depending on public systems social protection.

In general, however, entrepreneurship studies have developed around the individual and his subjective qualities, such as teamwork, being visionary, and taking calculated risks, as requirements for being a successful entrepreneur, not giving due importance to the knowledge of business techniques, such as business plan, sales price elaboration, job and salary management, financial reports, among others.

The search for defining the profile of the entrepreneur based the researches of economists and human behavior theorists. For the former, the focus of entrepreneurship is on the product, and consumers are encouraged to always want new things as dictated by the entrepreneur. Innovation emerges as one of the main attributes to the entrepreneur. For behaviorists or behaviorists, the focus is on the personality and behavior of the individual, where creative and intuitive attitudes are expressed such as: leadership, motivation, organization, profit vision, among others [1] \& [2]. These studies, however, as a reflection of market evolution, also began to consider training aimed at assisting the individual in the development of differentiated characteristics. Among these studies, we highlight: Souza and Fracasso (2006), Filion (1999) and McClelland (1972).

The entrepreneurial attitude is the autonomy to act, to lead, to work and the capacity to take risks [3]. It is the predisposition learned or not to act in an innovative, autonomous, planned and creative way. In both cases entrepreneurship is related to the abstraction of the human 
being different and special by nature, being ignored the fact that this human being will need to return to the real-life routine and manage his enterprise [4].

According to the data provided by SEBRAE [5], the preparation of the entrepreneur in terms of management, planning and business are highlights, as well as his experience and entrepreneurial profile that lead to a personal order for entrepreneurs to continue for the survival of companies.

The personality factors that characterize the entrepreneurial subjects as people, who can see opportunities where others can not, are commonly exploited in the scientific academic environment. However, if entrepreneurship is a genetic trait, entrepreneurs do not need anything else to succeed.

Based on the above, this research seeks to show that business training in the formation of managerial skills and competences is an essential condition for the development and maintenance of a company, for the ability to promote an interaction between learning in the affective and cognitive dimensions, providing absorption of full knowledge. The use of business training allows a multidisciplinary view, giving the participant the opportunity to develop a holistic view of the organizational structure.

In the work developed through the evaluation of the application of simulated training in the teaching process in universities in the United States, there are advantages in the use of these; among them, the greater fixation of the concepts presented in the training, when compared with the application of case studies and with traditional methods of teaching, as expository classes, used alone. In addition to promoting learning, the trainings stand out in the teaching of the General Administration and in the future development of the professional life of the individuals who are involved in these processes [6].

As a study, in order to prove the effects of training in entrepreneurship training, we based the data extracted from the SEBRAE-AP research "Impact of EMPRETEC Training on Macapaenses participants", which accompanied EMPRETEC participants in the two years following The results of the follow-up were credited to the theoretical and practical load that EMPRETEC, in its methodological philosophy focusing on the entrepreneur figure, places in the course of the process, which provides the participant student the "differential" in the competitive market.

\section{Entrepreneurship and Human Development}

The theme of entrepreneurship requires a holistic approach, deserving a prominence in the diverse economic, psychological and social approaches, considering that this is a multidisciplinary subject, this enables the researcher to the study not only in the historical part of the subjectas well as the essence of his philosophy and the science included in it, giving researchers the real notion of individual and general needs, and allowing the visualization that they are inseparable, and which serve as inspiration to man.
In this sense, the traditional training is characterized by a more theoretical and expository approach. Studies shows that the entrepreneurial training approach requires theoretical basis associated with educational activities practices by studying on entrepreneurship theme is common to make a deep theoretical about concepts, or even about the evolution historicaltion of this content. In order to understand more the entrepreneurship of the property, one must better understand the person of the entrepreneur, for that it is necessary a study of their attitudes and behaviors [7].

In the course of centuries, several theories on the study of the behavior and evolution of the human being were discussed, and every century they were progressing and changing the way of thinking the behavior according to the perception of new developments. A good example is the Cartesian thought of the seventeenth and eighteenth centuries is now considered limited compared to current thinking. When one analyzes the thoughts of environmentalists and structuralists who guided their discussion of "tabula rasa", in their studies, it said that nothing existed in the mind of a human being who had not passed through feelings, but over time were considered theoretical simplistic explanations. This current led to the Behaviorist theory with the reflex that relates the influence of the learned experiences behaviors.

On the other hand, the current called Gestalt or Inatism attributed the priority of their studies on perception, and this was the base category to explain the individual. The most important line of behaviorism thoughts envolvs environmental that inspires the human behavior to consider that the environment determines the subject, that is, the human being is the result of the environment in which born and grows and reproduces. While other currents like aprioristas, idealists, humani hese, gestalt, believes that the human being is responsible for determining the environment.

The entrepreneur is consided as a creative subject able to put into practices the idea and transformed into innovation [8]. Although with bias back to the environment, these studies have also shown that there are different cultural patterns of behavior, even under the same environmental influence, between entrepreneurs and non-entrepreneur [9].

This was the evolution of the study of human behavior and the environment which entrepreneurs lives, the transformation of them in this environment give rise to another school of thought called Interactionist or Constructivist, led by Piaget and Luria, Leontiev and Vygotsky. This actual current of the human being is in interaction with the environment they live in. Human relationships are the focus on the behavior and development of this medium as the processing agent and of itself. Companies with higher cultural level of individualism and assertiveness and lower cultural level of uncertainty avoidance and acceptance of inequality tend to favor Entrepreneurship [9].

The constructivist theory appropriates many past theories portraying and studies the evolution of human beings and their perceptions about the environment that their lives in, bringing up a more flexible approach in the current dialogue 
of the study of the human being, which now be termed as psychology of learning, this is focused on the reasons that lead the individual to submit a new behavior. Already the theoretical afore mentioned focus their research on the study of individuals in their age groups, that is, throughout his life and, therefore, are considered developmental.

It is important to note that in both pedagogy and psychology, beliefs and values must be observed to build the teaching and learning process, and these, in turn, directly affect the resulting practices or actions. Thus, by presenting a similar proposal in the development of these skills and competences, the teaching of entrepreneurship tends to become more relevant in management courses, since the future of the profile of the Administrator brings reengineering characteristics [10].

Concomitant to the studies of human behavior and its interrelationship with the environment, cognitive science emerged in the 1950s from the junction of different theories of different areas of knowledge, such as psychology, philophy, anthropology among others. Cognitive theory arises by relating the body to the mind, and reports that in order to progress in behavior and its understanding it is necessary to know the mind and especially to understand it well, to understand human behavior.

The unconscious is really who determines the form and direction of men, and also determines the evil in the construction of their own civilization. The author considers the analytical process as an endless therapy, due to the constant emergence of new conflicts in modern society [11].

Together with these scientific movements of the study of human behavior and its evolution with the environment in which it lives, theorists arise with a focus on pragmatism and market scenarios. Among the currents we can mention economists, who have considered the phenomenon of entrepreneurship as an inevitable consequence of the presence or absence of certain structural characteristics of the economy. Psychologists and anthropologists, as seen earlier, often consider entrepreneurial behavior as a consequence of genetic predispositions or as a result of long-term socialization processes.

In this sense, the focus on entrepreneurship is economic [12]. The economist is based on theory the premise of innovation to characterize an entrepreneur, the break with the old, the creation of new and especially the breach and creation for development. For him, the entrepreneur is responsible for the economic transformation. The phenomenon of economic development is in practice based on the fact that the data change and that the economy adapts continuously to them, then it can be affirmed that there is no economic development [2].

$\mathrm{T}$ herefore, in the view of economists is the product that began the transformation of the economic environment, and consumers are educated by this change in the product and its production, ie the consumer is the result of consumption and adapts as the imposition of this market, they are educated to always acquire new things like the imposition of the entrepreneur.
Another focus is behavioral [12] that cite as reference author McClelland who says that the entrepreneur is a person who organizes and maintains a business, bearing the risks of aiming for profits. It is someone who exercises some control over the means of production, producing more than can be consumed, in order to sell or exchange their production for individual or family income [13]. The author states in his studies that the human being is driven by a need for selfrealization and this need leads to society and the economy as a whole, and that this realization is intrinsic to every human being and is usually linked to the achievement of something difficult and which has great value for society.

In an overview, while economists tend to align entrepreneurship to innovation, the behavioral strand focuses on entrepreneurship as a creative and intuitive trait. However, both currents share, as a consequence of their hypotheses, the inefficiency of training focused on human behavior to form entrepreneurial characteristics in the short term in an individual or in a society.

Due to the positioning of these traditional currents that identify the phenomenon of entrepreneurship as a genetic consequence, or even as an only economic variable, for a very long period, scientific management was seen in the lack of studies focused on the development of entrepreneurial skills and competences, and treated the study of entrepreneurship as a natural phenomenon, diagnosing it as a genetic characteristic, which he called entrepreneurial characteristics [14]. Profiling the entrepreneur through his or her characteristics is so important that this may be the master line that will help entrepreneurs in fact identify the characteristics that must be perfected to be successful in their companies [15].

The growth of local markets in the last decades, globalization, technological innovation and the need to be always ahead in the competitive scenario, are making the authors see entrepreneurship as a multidisciplinary study and treat the theme in a much more comprehensive and dynamics. According to the author:

(...) By the emergence of entirely new production sectors, new ways of delivering financial services, markets and, above all, highly intensified rates of business, technological and organizational innovation. Flexible accumulation involves rapid changes in de-development patterns, both across sectors and across geographic regions, for example creating a broad employment movement in the so-called service sector, as well as in previously undeveloped regions(...) [14].

The impetus for this reorientation is also due to widespread frustration with the failure of structural interventions and credit programs to achieve the desired development goals. Along with this frustration has developed the concomitant recognition of the crucial role often played by individual behavior in the success or failure of particular endeavors. While most scholars recognize the importance of factors such as heredity, early education, culture, and the preponderant pattern of entrepreneurial spirit generation, perceptions of the role, nature, and relative scarcity of 
entrepreneurial activity have resulted in a growing interest in exploring the possibility of speeding up its development.

\section{The Aspects of Entrepreneurship}

The importance of entrepreneurship in growth and development of the economy has been confirmed and grounded on results of scientific research. This socioeconomic phenomenon has been described as a vector to generate employment and income. And while there are controversies, the inherent openness of new business has been considered positive for economic development in various countries and regions [16].

Contemporaneously, has been giving due importance to the study of entrepreneurship, much due to the economic crisis and the lack of jobs that each decade has been "haunting the population", especially in developing countries, thereby, increases the importance of studying entrepreneurship, and its formation in the teaching of entrepreneurship has been investigated and put into discussion by several authors, analyzing its origin, evolution, difficulties, used resources and legitimacy, among other issues [16].

Recently a study on the fundamental characteristics of entrepreneurship has been elaborated, and these are gathered in the areas or lines of thought: School of the great man; School of psychological characteristics; Classical School; School of Administration; School Leadership, Intrapreprehensive School.

The school of the great man suggests that entrepreneurship is a skill that belongs to the human being, intuitive or even a kind of "sixth sense" that accompanies the individual since birth. In turn, the school of psychological characteristics attributes characteristics to entrepreneurs such as: values, attitudes and unique needs, which are the elements of the entrepreneur's motivation, which makes them, enjoy the opportunities [17].

The classical school, led by Schumpeter's traditional thinking, deals with the figure of entrepreneurship directly linked to innovation as the entrepreneur's main characteristic. The school of management refers to the entrepreneur as the owner of a business or economic enterprise. The authors define the entrepreneur in the Leadership school as a born leader who is able to adapt according to the needs. And, finally, the school of intrapreneurship, which treats the subject as an entrepreneurial skill and competence and portrays the importance of these for the whole organizational complex.

The market evolution, free competition and strategic thinking that emerged with the process of change required a way of thinking about entrepreneurship and the formation of people who do not possess any "entrepreneurial characteristic", but not to the point of breaking with the range of knowledge left in the course of decades of study on the subject. The need to undertake allied to the study of management techniques aimed at the success of the enterprise, associated with new communication technologies and the evolution of information, have given rise to theories that think of the entrepreneur as a person that can be shaped by a process of learning.

Studies on training and human development in the Annual Psychology Review, demonstrated that the study of entrepreneurship, as formation through training, has progressed significantly both in terms of science and in practice. Therefore, companies are increasingly employing these trainings, containing case studies and interactive dynamics that change the motivation of those involved, always seeking new skills and individual skills of employees.

Through these training, there is an improvement in the perception and use of new opportunities through new combinations, allows the entrepreneur to offer new services, goods, production models or new raw materials [18]. Teachs that Entrepreneurship can not guarantee that potential students are all talented, precisely because it is a course of action. Scholars of the subject of entrepreneurial education have presented ways of teaching entrepreneurship in which it addresses both the part facing the development of attitudes and behaviors as focused on the skills and knowledge management [19].

The training can be seen as an administrative instrument of vital importance for increasing labor productivity, as well as a self-satisfaction factor training, constituting a proven motivator. However, when training is focused on entrepreneurship the emphasis is basically on expanding business plans, administrative skills and contact networks of aspiring entrepreneurs [20].

Although few authors maintain that behavioral training is sufficient to generate a significant increase in the quantity and quality of entrepreneurs, many argue that this training is a valuable and perhaps necessary element in any efforts that order. This argument seeks, above all, the groups that have yet to create a strong culture and its own history, and lay the foundation of individualism, innovation and entrepreneurial activity.

In this sense, in the entrepreneurial education programs:

The essential elements seem to be the development of imagination and creativity, as well as the ability to channel energy towards the goals that the entrepreneur wants to achieve. (...) there is a difference between training for the entrepreneur and management training, emphasizing the second case, the "skills to realistic dreams", rather than analytical skills. The entrepreneur also needs skills in communicating and establishing interpersonal relationships. Education for the entrepreneur should help the individual, in its development, by reinforcing its differentiated characteristics [21].

So, these factors give rise to the need to explore the possibility of deliberately accelerate the development of entrepreneurial skills more specifically focus on the knowledge and skills for business management. This set of factors makes that a new line of thinking about entrepreneurship focused on training through business training, people who are able to undertake and succeed, generating employment, income and stimulating the economy. 
Any individual can learn what it is to be a successful entrepreneur [22]. It is possible to train for entrepreneurial activity, with the purpose of realizing the individual as the main motivating force of entrepreneurial behavior [13].

In this sense, formally modified his thesis to discuss the importance of the sociocultural environment as a culminating variable in the formation of the entrepreneur and the importance of the entrepreneurial training to reinforce the fulfillment needs, having as main points in the discussion the formation of the entrepreneurial personality and to what extent this was an innate and immutable characteristic [13]. In his studies, the author reinforces the hypothesis that entrepreneurial motivations are subject to much more than temperament changes, in other words, suggests that social and environmental factors, including training, play an important role in encouraging latent motives, and that even training aimed at training entrepreneurs fulfills the role of stimulating the translation of mental dispositions into certain specific patterns of human behavior.

The socially oriented entrepreneur must seek the established balance between social and economic value, since economic value is considered crucial for the sustainability of social enterprises and also for the innovative creation of social value [23].

In McClelland's work called TMR "training motivational to perform [24]" in which the author conducts his research with many people, including ethnic groups and different ages in various countries, concludes that there is a relationship between capacity building and the trait of personality, which has been termed "personal entrepreneurial skills." McClelland research continues today, the most comprehensive programs developed with the intention of training entrepreneurs, and this has already undergone various tests and evaluations.

With McClelland study arise numerous training focused on training entrepreneurs, whose emphasis is to expand the future entrepreneurial vision through the business plan structure, the study focused on the main theories of administration through workshops and the implementation of studies practical case in order to bring the student pragmatism of business management and the formation of a network of contacts. However, always uses the Ancient discussions on int angíveis factors of personality and behavior of the entrepreneur. This factor has given rise to new lines of research applied to behavioral methods of business training, which is a relatively new field originating in developing countries.

\section{Methodology}

The types of surveys used in the preparation of this work were exploratory and descriptive.

The exploratory research "aims to provide the researcher a better understanding of the topic or research problem in perspective," can be used when you want to achieve the following objectives: Familiarize and raise the knowledge and understanding of a prospective research problem, help develop a priori information available related to a conclusive research problem to be performed or in progress, assist in the development or creation of relevant research issues for the intended purpose, assist in the determination of relevant variables to be considered in a research problem, classify concepts, assist in the design of the final research project, check whether similar research has been carried out, which methods were used and what the results obtained and set priorities for future research [25].

In view of the presented, in the first moment an exploratory research in scientific articles, master's dissertations and doctoral theses, on entrepreneurship, entrepreneurship training and development of people was developed, aiming at greater familiarity with the pro-posed problem.

In a second moment, the research was descriptive or explanatory. According to [25], "Descriptive or explanatory research is an exposition of the characteristics of a given population or a given phenomenon (...). It has, however, no compromise to explain the phenomena it describes, although it may serve as the basis for such an explanation. "

Thus, this research was dismembered with the objective of identifying and analyzing the value of entrepreneurship training as a tool for entrepreneurship training for the opening of micro and small enterprises, entrepreneurship training and for good corporate performance, including among young people.

For that, were applieds questionnaires, containing questions related to business startup, the formalization of these, the number of employees, turnover, among other questions focused on the objective of the research, and for monitoring was used the same questionnaire as for the research there the importance of collating data in time series.

These questionnaires were applied at the end of the training by the research department of the institution responsible for the "SEBRAE-AMAPÁ" project, where the EMPRETEC classes of 2010, four classes of 30 students, were established as a study object approximately 120 students who participated in the training. The number of participants in the survey was equal to the number of respondents in the questionnaire and was called the sample or experimental group, which was studied as a reference for our research.

All the work was done in the form of a field study through structured questionnaires not disguised, in order to evaluate the impact of the training. The first questionnaire had as objective to verify the evolution or temporal involution of the participants with respect to business practices variables, such as birth rate and mortality of enterprises, billing and etc.

After the application of the first follow-up questionnaire, students from the same previous group who answered the follow-up questionnaires applied by the SEBRAE-AP Research Center were established as a database. This research started in the second half of 2011 and ended in the second half of 2012, so the follow-up questionnaires were applied more two times totaling three de-nominated applications of $\mathrm{T} 0$ or initial questionnaire, T1 or first follow- 
up questionnaire and T2 or second follow-up questionnaire. The total number of respondents in the last two phases was 72 students or $60 \%$ of the population.

\section{Analysis of the Data}

In the database analysis of the intention to undertake (Table 1), the percentage of participants who did not have a company before the training (T0), either because they had never intended to open one, or because they first planned to train, is $57 \%$, and of these, $43.10 \%$ had never thought of starting a business of their own, that is, they had no intention of becoming an entrepreneur. However, at the first follow-up (T1) we realized that after training $100 \%$ of the sample surveyed started to intend to undertake, and $18.1 \%$ still wish to acquire more experience, so they prefer to wait for the right moment.

When we analyzed parameter 3 , in the final stage of follow-up (T2), we noticed that $97.2 \%$ of the sample surveyed already had a company, that is, after participating in the EMPRETEC training there was a birth rate increase of $54.1 \%$ percentage points and of course this fact can not be overlooked.

Table 1. Intention to undertake.

\begin{tabular}{|c|c|c|c|c|c|c|}
\hline \multirow{2}{*}{$\begin{array}{l}\text { VARIABLE } \\
\text { V1 }\end{array}$} & \multicolumn{3}{|c|}{ FREQUENCY } & \multicolumn{3}{|c|}{ PERCENTAGES } \\
\hline & T0 & T1 & T2 & T0 & T1 & T2 \\
\hline 1-I never thought of setting up a business itself. & 31 & 0 & 0 & 43.1 & 0 & 0 \\
\hline 2-I have thought of setting up your own business, but I prefer to gain experience & 10 & 13 & 2 & 13.9 & 18.1 & 2.8 \\
\hline 3-I already have a business. & 31 & 59 & 70 & 43 & 81.9 & 97.2 \\
\hline TOTALS & 72 & 72 & 72 & 100 & 100 & 100 \\
\hline
\end{tabular}

Source: Prepared by Author

The data confirm the effectiveness of the training, in the case study EMPRETEC, whose main objective is to develop the "entrepreneurial culture", the will to undertake, which confirms the argument that the training aimed at training entrepreneurs contribute to develop the propensity to undertake, it follows from the understanding that the training must have contributed to the difference in the opening of new companies.

Another factor that was demonstrated through the monitoring, and whose ignorance until then was cause of concern among the organizers of EMPRETEC, was evidenced, the quality of the open companies. The question was: to what extent have these companies been started in a consistent manner so that in a short time they will not be closed? This question was analyzed through the formalization factor of companies, taking into account that the exit of informality is attribute of quality of the company and of significant improvement of the profile of the entrepreneur. We can consider or denominate this phenomenon of conscious entrepreneurship, since the fact that an enterprise goes from informal to formal leads this to collect the due taxes and, consequently, to contribute to the development of their region.

The data provided in Table 2 provide additional support for the hypothesis that training contributes to the formalization of new firms.

The initial sample of the survey (T0) shows that $27.8 \%$ of the participants had informal companies before the training and that after that, in the "T2" monitoring, this percentage drops to $5.6 \%$, that is, a decrease of 22,2 percentage points of informal enterprises and at the same time a growth in the same proportion of formalized companies, taking into account only the companies opened before participating in the training.

Table 2. Entrepreneurial capacity.

\begin{tabular}{|c|c|c|c|c|}
\hline \multirow{2}{*}{$\begin{array}{l}\text { VARIABLE } \\
\text { V1 }\end{array}$} & \multicolumn{2}{|c|}{ FREQUENCY } & \multicolumn{2}{|c|}{ PERCENTAGES } \\
\hline & T0 & T2 & T0 & T2 \\
\hline 1-Formal has CNPJ & 11 & 66 & 15.3 & 91.7 \\
\hline 2-Informal not have CNPJ & 20 & 4 & 27.8 & 5.6 \\
\hline 3-Do not have company & 41 & 2 & 56.9 & 2.7 \\
\hline TOTALS & 72 & 72 & 100 & 100 \\
\hline
\end{tabular}

Source: Prepared by Author

As for the total formalization of companies, we noticed that only $15.3 \%$ of the firms opened before training were companies that owned CNPJ, while in the final time $91.7 \%$ of the organizations were already formalized, an increase of 76.4 percentage points, exceptional with regard to the withdrawal of companies from informality, which results in increased tax collection, formal jobs and income generation.

It should be noted that originally of the 72 enrolled only eleven stated to have formal company open before the training. As in the last follow-up the total number of students with a formal open company was $91.7 \%$, it is possible that of the existing companies only four have continued in informality and that the relevant ratio, considering only the old companies, is 7.35 to 1 . In other words, the correct ratio is 7.35 to 1 if the company already opened before enrollment remained open until the end of the follow-up.

In addition, the growth of formal open companies was 76.4 percentage points, while the growth in the number of informal enterprises has been interrupted, that is, new open companies are already born in the formality.

These data, in addition to being consistent with the hypothesis that participation in EMPRETEC stimulated the 
opening of new companies, suggest that the training may have helped to develop the capacity to undertake successfully, hence its relevance as a training tool. Finally, after participating in EMPRETEC, the sample generates, after the initial evaluation, 16.5 times more formal than informal enterprises (66 of 4).

Therefore, the data are clear in the conduction that after the participation in the training the entrepreneurial performance of the sample, understood in this article as the opening of an enterprise or economic activity, is significant.

In view of the data presented, the hypothesis is that entrepreneurial training aimed at training entrepreneurs is capable of transforming the behavior of the people who participate in them, being an opportunity to increase the relative number of open companies, formalize ventures and contribute to the improvement of its performance, with effects on the generation of income and its continuity and permanence in the competitive market.

The analysis of the data also reveals a clear change in the behavior of people, who began to see entrepreneurship as a new investment opportunity, a behavior that is evident after the preparation they went through before entering the market and seeking their independence of form conscious, with clarity of their future obligations and difficulties.

Therefore, the EMPRETEC Program fulfilled its role in the formation of new entrepreneurs, being also used as a tool for the continuous training of entrepreneurs with experience in the market in search of new knowledge, which makes them increasingly competitive in the market in which they operate.

\section{Conclusion}

Entrepreneurship study in the past decades has tended to the study of entrepreneurial characteristics and the intrinsic variables that led these people to succeed in the business scenario, but due to the need to generate employment and income, we started to study the entrepreneur as a person able to drive, to create new businesses, not simply because you want to undertake and succeed, but by economic development. Thus arises the need to create mechanisms to make these entrepreneurs, among these mechanisms highlight the business training, whose objective of creating entrepreneurs.

However, the big question was whether the practice is changing behavioral profile in participating in this type of training, which is based on the implications of business experience. Also emphasize the importance of evaluating a specific training that, in view of the research, is the most relevant in this line of thought.

The difficulty was how to identify its effectiveness, since was needed research per mitissem this type of measurement. Research SEBRAE-AP on behavioral change impacts on participants in the EMPRETEC 2010 held in the years 2011 and 2012, made possible the diagnosis. But can not fail to highlight the fact that the survey had located only made in a state and have had a limited number of participant may have caused a certain limitation in the study, which would be future proposal to expand the population studied and also the geographic region of the impact of research.

The main idea of the research, which is based on the Intrapreneurship school, which has in one of its main theorists, is that any individual can learn what it is to be a successful entrepreneur without presenting factors personality and behavior [26].

This argument was evident from the data collected from those participating in the EMPRETEC training, a $97.2 \%$ increase in the number of companies open and a $76.4 \%$ increase in the number of companies formalized over a period of two years.

From SEBRAE's research, strong perceptions such as the benefits caused by the introduction of the process of coexistence and intra-group relationship for the good functioning of a company, to help in making decisions as well as in the recognition of the consequences of a decision taken in the wrong way, which leaves the participant with a census of responsibility and the notion of the dimension in his business life of the consequences of a qualified decision to me.

The "zero-mortality" rate of this group during the two years of research is particularly noteworthy because it has not occurred in any of the SEBRAE-AP surveys on mortality and birth rates since they were be elaborated.

It was also observed the change in the way participants perceived entrepreneurship after the experience they had during the training, evidenced by the increase in the number of formalized companies, as demonstrated in the follow-up study. This consistency should be highlighted and compatible with the position of Professor Josir Simeone Gomes, who believes that solidifying a company, particularly a small company, in the market "can only be a matter of planning, at least this is the basis for sustaining it." The main problem would be the lack of knowledge to implement, control and evaluate project performance and lack of managerial capacity [27].

Based on the results of the data analysis of this research, we can propose that the EMPRETEC business training achieves its objective of stimulating entrepreneurship in the participants, regardless of the area in which they study, but rather the stimulus they obtain to undertake, of it with success. Similarly, the hypothesis is that students who participate in this type of training are more likely to engage than people who do not participate. Even those of other nonentrepreneur-oriented formations, those who do not have as much initiative, or proactivity, even those who are not wellstaffed or do not know how to listen, who have no idea shine, or who did not excel in school or college, but who, when participating in trainings such as EMPRETEC, become familiar with concepts and simulated practice that tend to become important differentials in the search for opportunities in the market, as employers or as employees.

Still, EMPRETEC is a training with experience of business activities, containing concepts, rules and organizational criteria, such as all entrepreneurial training aimed at training 
entrepreneurs, the article contributes to a favorable evaluation of the study training, as an important training tool and development of entrepreneurs, and points out that such methods could be used more frequently in undergraduate and executive training courses not only in Amapá but also in Brazil.

\section{References}

[1] Say, JB (1983, April). Political Economy Treaty - Collection Eco nomistas. São Paulo.

[2] Schumpeter, JA (1976). Capitalism, Socialism and Democracy. New York Harper Perennial, USA. Shinnar, RS; Giacomin, O. \& Janssen, F. (2012, may). Entrepreneurial Perceptions and Intentions: The Role of Gender and Culture. Entrepreneurship Theory and Practice, p. 465-492.

[3] Hartman, A. Evaluation of intrapreneurial culture: development and testing of a methodology. 2006. $380 \mathrm{f}$. Thesis (MA), Graduate in Production Engineering Program, Department of Production Engineering (PPGEP), Technological University of Paraná, Ponta Grossa

[4] Souza, \& ECL Failure (2006). E. Entrepreneurship: concepts, approaches, road building the measurement scales. In press.

[5] SEBRAE - The Sebrae Entrepreneurial Education proposal (2017) [internet] Available at

$<$ https://www.sebrae.com.br/sites/PortalSebrae/sebraeaz/aproposta-deeducacao-empreendedora-dosebrae,b741be061f736410VgnVCM2000003c74010aRCRD> Accessed on 07/22/18.

[6] Therlandeli, R.. (2001) A set of companies involving logistics chain: Game F61 - An educational approach. Master's thesis at the University of Production Engineering Fede ral of Santa Catarina.

[7] Ruskovaara, E.; P ihkala, T.; Rytkola, T. \& S eikkula-Leino, J. (2010 august). "Studying Swings, E.; C annon -B owers, J.. (2001) The science of training:. A decade of progress Annual review of psychology, vol. 52, p. 471-499.

[8] Hitt, MA; I Reland, RD \& Hoskisson, RE (2011) Strategic Management: Competitiveness and Globalization. 2 ed, S. Will Paul: Cengage Learning.

[9] Shinnar, Rachel, O., Giacomin, \& Frank, J. (2012). Entrepreneurial Perceptions and Intentions: The Role of Gender and Culture. Entrepreneurship Theory and Practice, 36(3), 465-49.

[10] Loptions, RMA (2010). Benchmarks for Education Entrepreneur. In: LOPES, RMA (Org.) Entrepreneurial Education: concepts, models and practices, p. 17-44, Rio de Janeiro, Elsevier.

[11] Freud, S. (1978). Five lessons of Psychoanalysis. Cultural April. São Paulo (Collection Thinkers), 246 p.

[12] Filion, LJ, \& Bourion, C. (2008). Les représentations entrepreneuriales. In: revue internale of psychosociologie. Paris: Éditions ESKA. 2008, p.13-43.
[13] McC lelland, DC (1972). The competitive society: achievement and social progress. Rio de Janeiro: $E d$. Expression and Culture.

[14] Harvey, L., Locke, W. and Morey, A., 2002, Enhancing Employability, Recognising Diversity. London, Universities UK.

[15] Filion, LJ (1999). Entrepreneurship as Theme in higher studies. In: entrepreneurship, science, technology and art. Brasilia: CNI / IEL National, 1999, p. 13-43.

[16] Rocha, ELC; B Acchi, GA; G uerra, DS; R Hello J UNIOR IN \& P oney, DRC (2011). Entrepreneurship education in undergraduate on- site courses in Management in Singapore: A Study of Content and Pedagogical. Magazine Administration: Education and Research (RAEP), v. 12, p. 393-414.

[17] Souza, ECL (2005). Entrepreneurship: Genesis of the contemporaneity. In: Studies EGEPE-Meeting on Entrepreneurship and Small Business Management, 4, Curitiba, p. 134-146.

[18] Fontenele, RES; M Oura, HJ \& L eocadio, AL (2011, Sept / Oct) Human Capital, Entrepreneurship and Development: Empirical Evidence in the Ceará municipalities. Mackenzie Administration Journal, São P aulo, V. 12, No. 5.

[19] Mason, C. (2011, january). Entrepreneurship Education and Research: emerging trends and concerns. Journal of Global Entrepreneurship, v. 1, no. 1.

[20] Magalhães, ML \& B Orges AJE (2001). Self and peer assessment in the diagnosis of training needs. Psychological Studies, Vol. 6 (1), 33-50.

[21] Filion, LJ (1997). From Entrepreneurship to Entreprenology. In: usasbe annual national conference. California. Proceedings... Wisconsin: Usasbe 1997.

[22] Dornelas, JCA (2012). Only courage is not enough: to pursue opportunities people do not need a special gift. Available in: http://www.stratusbr.com/BR/empreendedor.artigo.asp. Accessed on 05/10/2012.

[23] Muñoz, P.; Kibler, E. (2016) Institutional complexity and social entrepreneurship: a fuzzy-set approach. Journal of Business Research, Amsterdam, v. 69, n. 4, p. 1.314-1.318.

[24] McClelland, DC (1961). The Achieving Society. New York: The Free Press.

[25] Vergara, SC (2009). Projects and Management Research Report. 11. ed.São Paulo: Atlas, 20.

[26] Dornelas, JCA (2012). Only courage is not enough: to pursue opportunities people do not need a special gift. Available in: http://www.stratusbr.com/BR/empreendedor.artigo.asp. Accessed on 05/10/2012.

[27] Kopschitz, I. (2004, February). How to maintain healthy small business. O Globo newspaper. Rio de Janeiro, notebook Good Chance. 